\title{
Setting of a procedure for experimental incubation of Pacific oyster (Crassostrea gigas) embryos
}

\author{
M. Suquet ${ }^{1,{ }^{*}}$, C. Amourda ${ }^{1}$, C. Mingant ${ }^{1}$, I. Quéau ${ }^{1}$, L. Lebrun ${ }^{1}$ and R. Brizard ${ }^{2}$ \\ ${ }^{1}$ Ifremer, Station Expérimentale d'Argenton, Département PFOM, 11 presqu'île du vivier, 29840 Argenton, France \\ ${ }^{2}$ Ifremer, Département AGSAE, Ronce les Bains, 17390 La Tremblade, France \\ *: Corresponding author : M. Suquet, email address : msuquet@ifremer.fr
}

\begin{abstract}
:
Standardized experimental protocols designed to study Pacific oyster (Crassostrea gigas) gamete quality have not been previously published. Gamete sampling variations and confounding effect of interacting factors result in large variations between replicates, decreasing the effects of the studied factors. This work aims at defining a standardized procedure for incubation of oyster embryos designed for experimental purposes.

In a first phase, four experiments were developed to improve embryos sampling and handling. They showed that a minimum of 50 embryos must be counted to decrease the variation between counting replicates. For reliable results, sampling must be carried out from 0 to 7 minutes after a careful agitation of seawater containing embryos (salinity: $35.6 \%$ ). Compared to control and a $30 \mathrm{~cm}$ one, the D-larval yield of embryos submitted to a $1 \mathrm{~m}$ fall was significantly reduced, showing the limited effect of mechanical disturbance on Pacific oyster oocytes survival. Then, maintaining 2.2 million embryos in $250 \mathrm{ml}$ seawater for a two hours period resulted in a decrease of D-larval yield which could not be explained by a decrease of $\mathrm{O} 2$ content and $\mathrm{pH}$ of seawater.

The second phase of this work included a set of five experiments, defining experimental incubation conditions. A higher larval yield was observed using $1.8 \mathrm{l}$ beakers and $150 \mathrm{l}$ tanks compared to $0.3 \mathrm{ml}$ microtiter plates and $1 \mathrm{l}$ fish egg incubators. Higher larval yields were recorded when embryo density ranged from 5 to $100 . \mathrm{ml}-1$, compared to values between 500 and 2000. ml-1. Compared to controls (no antibiotic or no presence of light), no changes of D-larval yield were observed by adding $20 \mathrm{ppm}$ chloramphenicol or by maintaining embryos in total darkness. Then, a significant decrease of $\mathrm{pH}$ and O2 content was observed during the incubation period. However, these changes could not be considered as limiting for Pacific oyster embryo development.

In conclusion, experimental incubation conditions have been defined in this study: 30 embryos.ml-1 incubated in 1.8 l beakers without antibiotic and regardless of light intensity, when not higher than 500 lux. The mean coefficients of variation observed between tank replicates ranged from 13.1 to $16.5 \%$. The standardized incubation procedure described in this work will help to study quality variations of Pacific oyster gametes.
\end{abstract}

Keywords: Incubation; Embryo; Experimental; Pacific oyster; Crassostrea gigas 


\section{Introduction}

The evaluation of gamete quality is essential to breeding control and to develop aquaculture productions. Research devoted to gamete quality in molluscs remain limited and especially in Pacific oyster (Crassostrea gigas; Valdez Ramirez et al., 1990; Faure, 1996): the very high fecundity observed in male and female of this species did not support such studies since high quantities of larvae are easily obtained regardless of gamete quality. However, a high individual variance was observed in parental contribution to reproductive success which can be partly attributed to gamete quality (Boudry et al., 2002). Large individual differences in post-thaw sperm motility and fertilization capacities were also reported (Dong et al., 2005), suggesting variations in gamete quality. Both observations sustain subsequent experimental studies of gamete quality in Pacific oyster in order to improve their management and facilitate selective breeding plans. However, a standardized experimental incubation protocol designed to study gamete quality in Pacific oyster is still lacking.

The development of incubation methods designed for experimental purposes aims at setting i) reliable rearing conditions reducing the concurrent effects of uncontrolled parameters and ii) practical rearing conditions well adapted to targeted species and research requirements. This requires reliable gamete sampling techniques designed to distribute gamete precisely and highly controlled rearing conditions. Such protocols provide hatching rates with a low variation between replicates, highlighting hatching differences between egg lots. Compared to farming practices, experimental incubation protocols use a large number of small egg lots, required for testing the effect of different conditions using replicates and for statistical data analysis.

Experimental incubation methods have been mainly published for fish eggs. Reliable hatching rates were recorded by Devauchelle et al. (1986) using experimental devices designed for incubation of marine fish eggs. 96-well microtiter plates were used for experimental incubation of seabream (Sparus aurata), seabass (Dicentrarchus labrax) and white seabream (Diplodus sargus) eggs, allowing reliable individual monitoring of hatching performances with low space and costs constraints (Panini et al., 2001). Complete insemination and incubation experimental procedures of turbot (Psetta maxima) eggs were described by Suquet et al. (1995), defining reliable gamete sampling and counting techniques, sperm management procedures and rearing conditions. Pacific oyster embryos were used to assess marine water quality because they are highly sensitive to pollutants. Bio-assays were efficiently performed including incubation in laboratory conditions (His et al., 1997; Quiniou et al., 2007). Experimental protocols for Pacific oyster egg incubation were described in some published studies (Renard, 1991; McFadzen, 1992; Dong et al., 2005; Tervit et al., 2005). However, these experimental protocols were not standardized by defining the effects of rearing conditions on D-larval survival.

This work aims at defining a standardized procedure for the incubation of Pacific oyster embryos for experimental purposes. It includes two phases: firstly, the improvement of sampling and handling techniques of embryos and secondly, the setting of incubation conditions such as tank volume, embryo density, presence or absence of light or antibiotic. The effects of these factors must be studied when setting a finely controlled experimental incubation protocol. 


\section{Material and methods}

\subsection{Oyster conditioning and gamete stripping}

From March to August 2006, three lots of adult oysters were collected from the Aber Benoît estuary (North Brittany, France). They were transferred to the Argenton experimental hatchery and conditioned in flow through seawater tanks according to Chavez-Villalba et al. (2002). After 6 to 8 weeks, gametes were collected by gonad dissection of ripe animals, filtered using a $60 \mu \mathrm{m}$ mesh size and diluted in $1 \mathrm{l}$ test tube filled with seawater filtered at $1 \mu \mathrm{m}$. After a careful mixing, oocyte concentration was assessed from triplicate $50 \mu \mathrm{l}$ samples. Then, oocytes were fertilized in $5 \mathrm{l}$ beakers by addition of sperm collected from two or three males $(300 \mathrm{ml}$ sampled from a 1 l suspension in filtered seawater for each male). The presence of 3 to 5 spermatozoa around each oocyte was verified under a microscope. The fertilization rate, assessed 2 hours after fertilization by observing three $50 \mu \mathrm{l}$ samples, ranged from 65 to $100 \%$, depending on spawn. Embryos were then transferred in incubation facilities and maintained at a constant temperature of $22^{\circ} \mathrm{C}$. Neither water renewal nor aeration were provided to incubators. When not stated, standard incubation conditions were used: $1.8 \mathrm{l}$ beakers and a density of 30 embryos. $\mathrm{ml}^{-1}$. The D-larval yield [(the number of D-larvae/the total number of embryos)x100] was estimated after 48h. Non viable larvae (translucent or non D-shaped) were not included in the estimated number of D-larvae.

\subsection{Experimental design}

All experiments were carried out using three individual spawn and incubation was performed in triplicates.

\subsubsection{Sampling and handling techniques of embryos}

Four experiments were conducted during the first phase of the present study. Firstly, to improve counting reliability, the effect of embryo number on the coefficient of variation between counting replicates was studied: one hour post fertilization, embryos were diluted in five increasing volumes of seawater (from $100 \mathrm{ml}$ to $1 \mathrm{l}$ ). The coefficient of variation between counting triplicates was assessed in relation with increasing embryo density $(10,20,30,50$ and $80 /$ replicate) in $40 \mu$ l samples. In a second experiment, the sinking kinetic of embryos in seawater (salinity: $35.6 \%$ ) was determined one hour post fertilization in order to standardize embryo agitation and counting: embryo distribution was homogenised by a $60 \mathrm{~s}$ agitation in a $500 \mathrm{ml}$ test tube containing seawater. The number of embryos was assessed at $0,1,3,7,15$ and 30 minutes after agitation, using triplicate $40 \mu \mathrm{l}$ samples taken at the surface of the test tube. In a third experiment, the effect of a mechanical stress was assessed since embryos are submitted to shocks during handling procedures: 45,000 embryos maintained in 1.81 seawater were collected two hours after fertilization on a $20 \mu \mathrm{m}$ mesh size after a $30 \mathrm{~cm}$ or $1 \mathrm{~m}$ vertical drop in a polyvinyl chloride plastic tube. Embryos were then transferred to incubators. The D-larval yield of mechanically stressed embryos was compared to results observed in unstressed embryos (control: no vertical drop). Fourthly, the effect of a transient high embryo density on subsequent Dlarval yield was described since this could be used during experimental protocol. One hour after its adding for fertilization, sperm was discarded using embryo filtration on a $20 \mu \mathrm{m}$ mesh size. 2.2 millions of embryos of each of the three spawn were transferred to a $250 \mathrm{ml}$ test tube and maintained at this high concentration without water renewal or aeration. Then, successive samples of embryos were transferred from test tubes to incubation facilities after 1,2, 3.5, 5 and $24 \mathrm{~h}$. In order to monitor environmental changes during the transient high embryo density phase, oxygen concentration $\left(\mathrm{mg} . \mathrm{I}^{-1}\right)$ and $\mathrm{pH}$ were assessed after a careful agitation of test tube volumes at each sampling, using respectively Bioblock WTW Oxi 340 and Bioblock WTW pH 340. 


\subsubsection{Setting of incubation conditions}

Five experiments were carried out during the second phase of this work. Firstly, to determine the optimal tank volume, embryos were incubated at a same density and in different containers: $0.3 \mathrm{ml}$ microtiter plates, $30 \mathrm{ml}$ flasks, $1 \mathrm{l}$ cylindroconical incubators used for fish eggs, $1.8 \mathrm{l}$ beakers and $150 \mathrm{l}$ cylindroconical tanks. Secondly, to determine optimal rearing density, embryos were incubated at

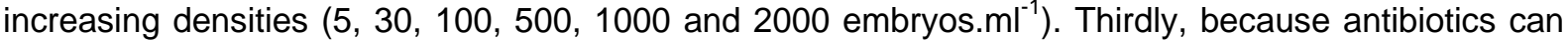
be used in molluscs rearing, the D-larval yields of samples incubated with 20ppm chloramphenicol (1g antibiotic diluted in $50 \mathrm{ml}$ ethanol and transfer of $1.8 \mathrm{ml}$ in each $1.8 \mathrm{l}$ beaker) or without chloramphenicol (control) were compared. The fourth experiment aimed at determining the effect of light by comparing the D-larval yields of samples incubated with artificial light (control: 500 lux) or in total darkness. Fifthly, to monitor environmental changes during the incubation phase, oxygen concentration and $\mathrm{pH}$ were measured in standard incubation conditions defined during this study, in triplicate beakers and for three spawn at $0,24,30$ and $48 \mathrm{~h}$ after embryo transfer in beakers.

\subsection{Statistics}

After angular transformation, variance homogeneity was verified using Bartlett test. Then, results were compared using a two way ANOVA (studied factor and spawn). When differences were significant, a Tukey a posteriori test was used for comparison.

\section{Results and discussion}

During the first phase of this study, a significant decrease $(P<0.05)$ of the coefficients of variation between replicates was observed when the mean number of embryos counted per replicate was increased from 10 to 50 (Fig.1a). At a salinity of $35.6 \%$, a significant decrease $(P<0.001)$ of embryo number was observed 15 minutes after agitation (Fig.1b). Furthermore, a significant interaction was observed between time after agitation and spawn $(P<0.001)$. As a consequence, embryo sampling must be carried out from 0 to 7 minutes after a careful agitation of seawater volume. Compared to control and $30 \mathrm{~cm}$, a $1 \mathrm{~m}$ fall of embryos significantly $(\underline{P<0.05})$ reduced the $D$-larval yield (Fig.1c). A significant $(P<0.05)$ interaction was observed between mechanical stress conditions and spawn. Pacific oyster embryos are moderately sensitive to mechanical stress since their development was not modified by a $30 \mathrm{~cm}$ fall on a mesh. Six hours after fertilization, salmon (Salmo salar) egg dropping from a height ranging from 18 to $39 \mathrm{~cm}$ caused a 10\% mortality (Krise, 2001). As observed in salmon, individual sensitivity to mechanical stress differs between oyster spawn, suggesting a potential quality criterion of embryos. Egg resistance to mechanical damage depends on their envelope thickness (Loening et al., 1988). Pacific oyster egg ultrastructure remains poorly described and its envelope thickness is not precisely reported.

A significant $(P<0.001)$ decrease of $D$-larval yield was observed when maintaining 2.2 millions of embryos in a test tube for a transient two hours period inducing a $25 \%$ decrease of $D$-larval yield. After $24 \mathrm{~h}$, the D-larval yield was not higher than $10 \%$ (Fig. 2a). Furthermore, a significant $(P<0.05)$ interaction between embryo exposure to transient high density condition and spawn was recorded. When pooling results recorded for the three spawn, a significant decrease of oxygen content $(\underline{P<0.001})$ and $\mathrm{pH}(\underline{P<0.001})$ measured in the test tube with time was observed (Fig. $2 \mathrm{~b}$ and $2 \mathrm{c})$. The rapid decrease of $D$-larval yield observed when maintaining embryos at a high density must be taken into account during experiments: for longer duration protocols embryos must be diluted in seawater. The cause of larval yield fall remains problematic because $\mathrm{O}_{2}$ and $\mathrm{pH}$ values assessed after 2 hours for both parameters (respectively $7.3 \pm 0.1 \mathrm{mg}^{-1} \mathrm{ml}^{-1}$ and $8.16 \pm 0.01$ ) could not be considered as limiting ones for oyster D-larvae.

During the second phase of this study, a significantly $(P<0.001)$ higher D-larval yield was observed for $1.8 \mathrm{l}$ beakers and $150 \mathrm{l}$ tanks compared to $0.3 \mathrm{ml}$ microtiter plates and $1 \mathrm{l}$ fish egg incubators (Fig.3a). This result was not significantly different from values observed in $30 \mathrm{ml}$ flasks. A significant $(P<0.001)$ interaction was recorded between tank volume and spawn. A significantly $(P<0.001)$ higher $D$-larval yield was observed for embryo densities ranging from 5 to $100 \mathrm{ml}^{-1}$, compared to values comprised between 500 and 2000. $\mathrm{ml}^{-1}$ (Fig.3b). A significant $(\underline{P<0.05})$ interaction 
was recorded between embryo density and spawn. Compared to controls (respectively no chloramphenicol and presence of light), significant changes in D-larval yield were recorded neither when adding 20 ppm chloramphenicol (Fig.4a) nor when maintaining embryos in total darkness (Fig.4b). The effect of light on survival of Pacific oyster embryos has not been reported in the literature. In abalone (Haliotis asinina), no significant effect of this parameter was reported during a 20h incubation period (Ladja, 2000). Adding chloramphenicol did not increase Pacific oyster larval survival at a low embryo density of $30 \mathrm{ml}^{-1}$. In opposition to scallop (Pecten maximus) larvae, the growth rate of oyster larvae was not improved using different antibiotics including chloramphenicol (Nicolas and Ansquer, 1995).

During the incubation phase, a significant decrease of $\mathrm{O}_{2}$ content $(\mathrm{P}<0.001)$ was observed after 24 and $48 \mathrm{~h}$ and after 30 or $48 \mathrm{~h}(\mathrm{P}<0.001)$ for $\mathrm{pH}$ (Fig. $5 \mathrm{a}$ and b). A significant interaction $(\mathrm{P}<0.001)$ was recorded between $\mathrm{pH}$ decrease with time and spawn. However, theses changes cannot be considered as limiting for embryo development because high values of both parameters are still assessed after $48 \mathrm{~h}\left(\mathrm{O}_{2}: 7.3 \pm 0.0 \mathrm{mg}^{-1} \mathrm{ml}^{-1}, \mathrm{pH}: 8.10 \pm 0.00\right)$.

\section{Conclusion}

Incubation conditions of Pacific oyster embryos used for experimental purposes have been defined in this study: 30 embryos. $\mathrm{ml}^{-1}$ incubated in 1.81 beakers without antibiotic and regardless of light intensity when comprised between 0 and 500 lux. When handled, moderate stress can be applied to embryos and a minimum of 50 embryos must be counted in order to record reliable results.

The mean coefficients of variation observed between replicates, after the standardization of the incubation protocol carried out in this study, ranged from 13.1 to $16.5 \%$. Using incubation conditions defined in this work, oocytes collected from one female may be used for 50 to 350 experimental lots, depending on oyster fecundity.

The standardized incubation procedure described in this work will help to study gamete quality variations in Pacific oyster and will facilitate the setting of selective breeding plans.

\section{Acknowledgements}

The present study was funded by Ofimer (project Triplofimer). The authors want to thank F. Quiniou and J. Normand (Ifremer) for fruitful discussions on the protocols and three anonymous referees for their constructive suggestions.

\section{References}

Boudry, P., Collet, B., Cornette, F., Hervouet, V., Bonhomme F., 2002. High variance in reproductive success of the Pacific oyster (Crassostrea gigas, Thunberg) revealed by microsatellite-based parentage analysis of multifactorial crosses. Aquaculture 204, 283-296.

Chavez-Villalba, J., Pommier, J., Andriamiseza, J., Pouvreau, S., Barret, J., Cochard, J.C., Le Pennec, M., 2002. Broodstock conditioning of the oyster Crassostrea gigas: origin and temperature effect. Aquaculture 214, 115-130.

Devauchelle, N., Letty, Y., Quere, M., 1986. Experimental units for incubation and larval rearing with special reference to four marine fish species. Aquaculture 58, 297-304.

Dong, Q., Huang, C., Eudeline, B., Tiersch, T., 2005. Systematic factor optimisation for cryopreservation of shipped sperm samples of diploid Pacific oysters, Crassostrea gigas. Cryobiol. 51, 176-195. 
Faure, C., 1996. Paramètres physiologiques de l'émission et de l'activation des gamètes mâles de deux mollusques bivalves, la coquille Saint Jacques Pecten maximus (L.) et l'huître creuse Crassostrea gigas (Thunberg). Thesis, Univ. Paris 7, 255p.

His, E., Seaman, M.N.L., Beiras, R., 1997. A simplification of the bivalve embryogenesis and larval development bioassay method for water quality assessment. Wat. Res. 31, 351-355.

Krise, W.F., 2001. Sensitivity of Atlantic salmon eggs to mechanical shock during the first six hours after fertilization. N. Am. J. Aquacult. 1, 34-37.

Ladja, J.A.M., 2000. The effect of stocking density, temperature and light on the early larval survival of the abalone Haliotis asinina (Linne). J. Shellfish Res. 1, 524-525.

Loening, S., Kjorsvik, E., Falk-Peterson, I.B., 1988. A comparative study of pelagic and demersal eggs from common marine fishes in Northern Norway. Sarsia 1, 49-60.

McFadzen, I.R.B., 1992. Growth and survival of cryopreserved oyster and clam larvae along a pollution gradient in the German Bight. Mar. Ecol. Progr. Ser. 91, 215-220.

Nicolas, J.L., Ansquer, D., 1995. Axenic bivalve larvae for study of pathology and effect dissolved organic matter. In: Barret, J., Dao, J.C., Lubet, P. (Eds.), Proc. of the $8^{\text {th }}$ International Pectinid Worshop, 22-29 May, Cherbourg, France. Actes de colloques Ifremer 17, 264.

Panini, E.B., Mylonas, C.C., Zanuy, S., Carillo, M., Ramos, J., Bruce, M.B., 2001. Incubation of embryos and larvae of marine fish using microtiter plates. Aquac. Int. 9, 189-195.

Quiniou, F., Damiens, G., Gnassia-Barelli, M., Geffard, A., Mouneyrac, C., Budzinski, H., Roméo, M., 2007. Marine water quality assessment using transplanted oyster larvae. Env. Int. 33, 27-33.

Renard, P., 1991. Cooling and freezing tolerances in embryos of the Pacific oyster, Crassostrea gigas: methanol and sucrose effects. Aquaculture 92, 43-57.

Suquet, M., Gaignon, J.L., Quéméner, L., Normant, Y., 1995. Artificial insemination of turbot (Scophthalmus maximus) eggs: a procedure for experimental purposes. In: Lavens, P., Jaspers, E., Roeland, I. (Eds.), Larvi'95, EAS, Sp. Publ. 24, 57-59.

Tervit, H.R., Adams, S.L., Roberts, R.D., McGowan L.T., Pugh, P.A., Smith, J.F., Janke, A.R., 2005. Successful cryopreservation of Pacific oyster (Crassostrea gigas) oocytes. Cryobiology 51, 142-151.

Valdez Ramirez, M.E., Le Pennec, M., Dorange, G., Devauchelle, N., 1990. Assessment of gamete quality in the Pacific oyster Crassostrea gigas. Invertebr. Reprod. Dev. 36, 73-78. 


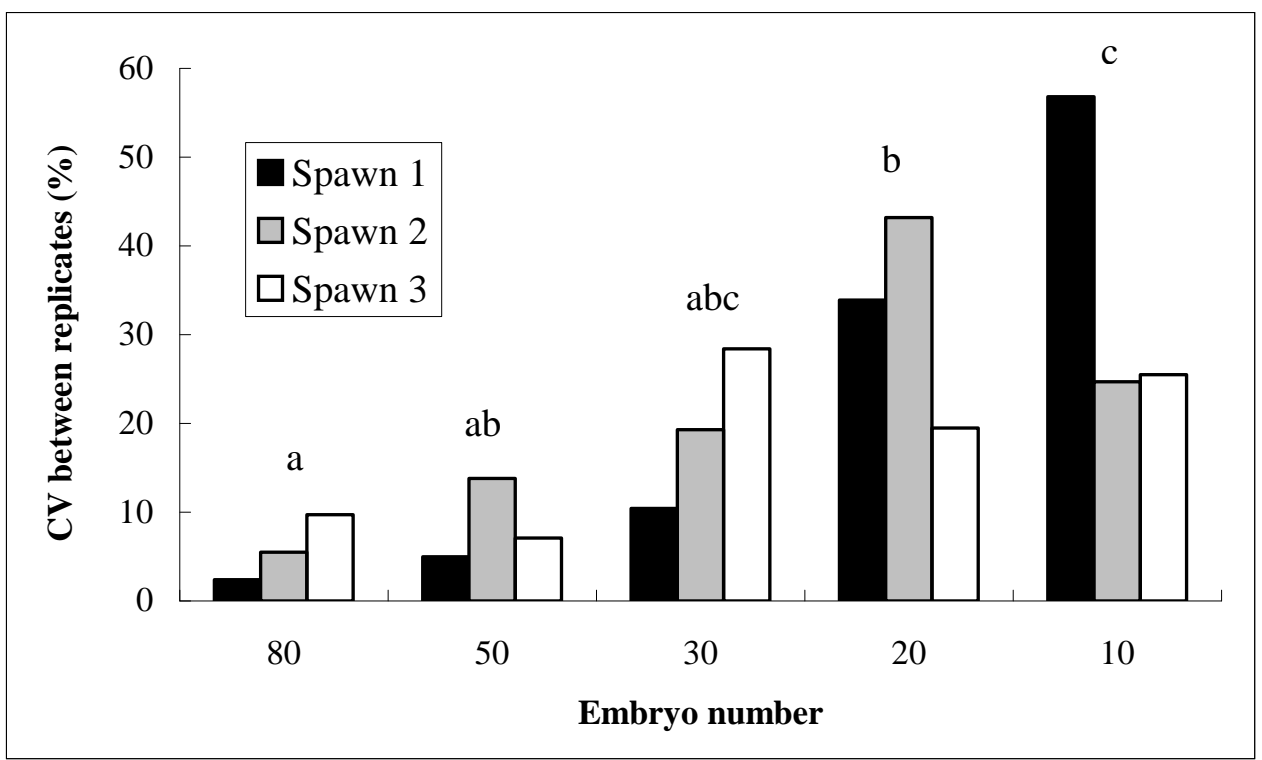

Fig.1: Changes in the coefficients of variation (CV) between counting replicates in relation with sample embryo density (different letters refer to significantly different results).

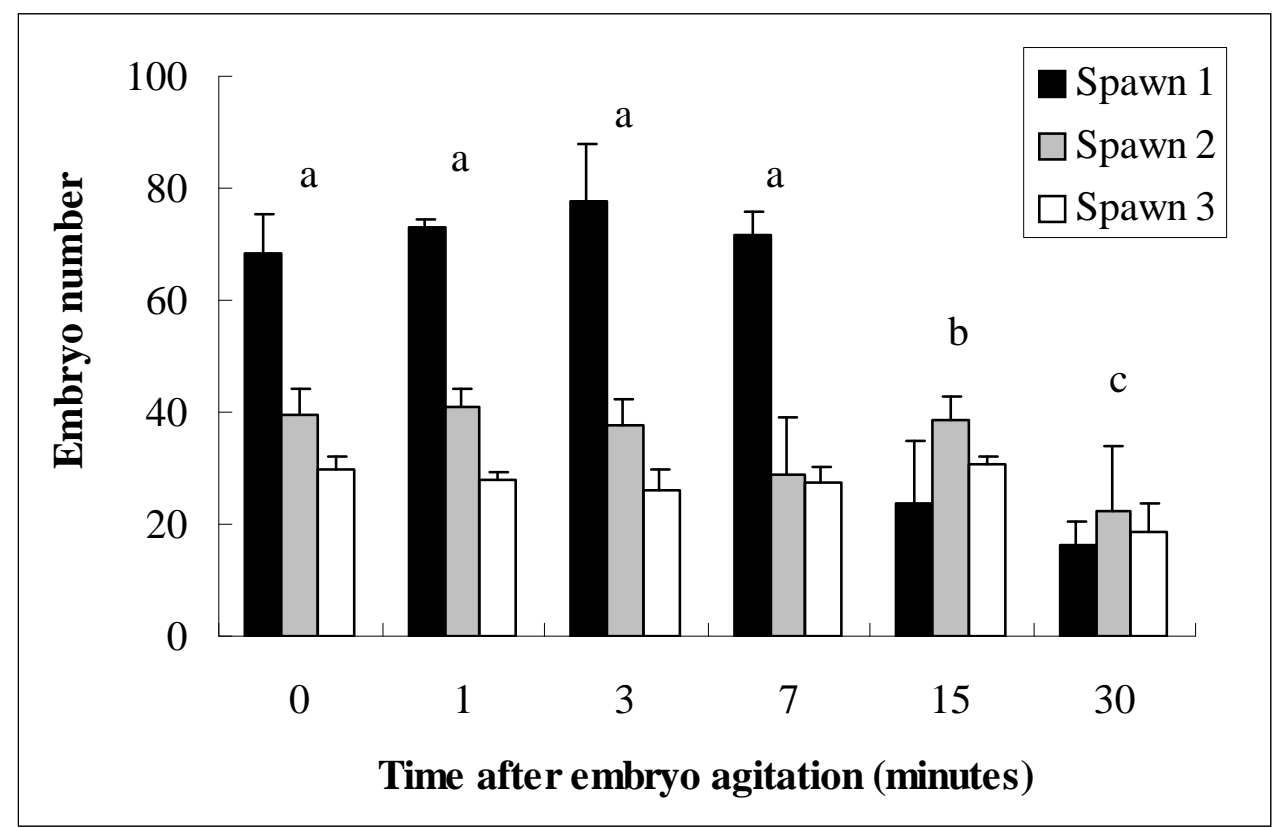

Fig.2: Changes in embryo number in relation with time after agitation (different letters refer to significantly different results). 


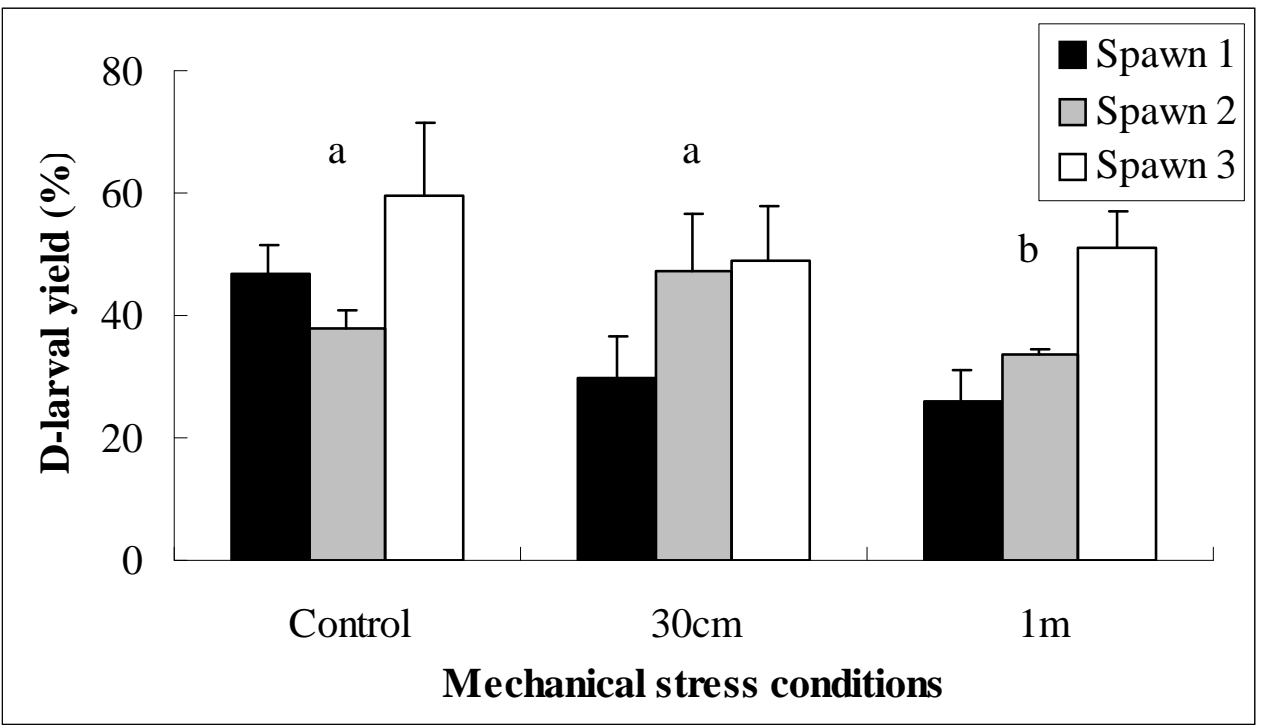

Fig.3: Effect of mechanical stress on D-larval yield (different letters refer to significantly different results).

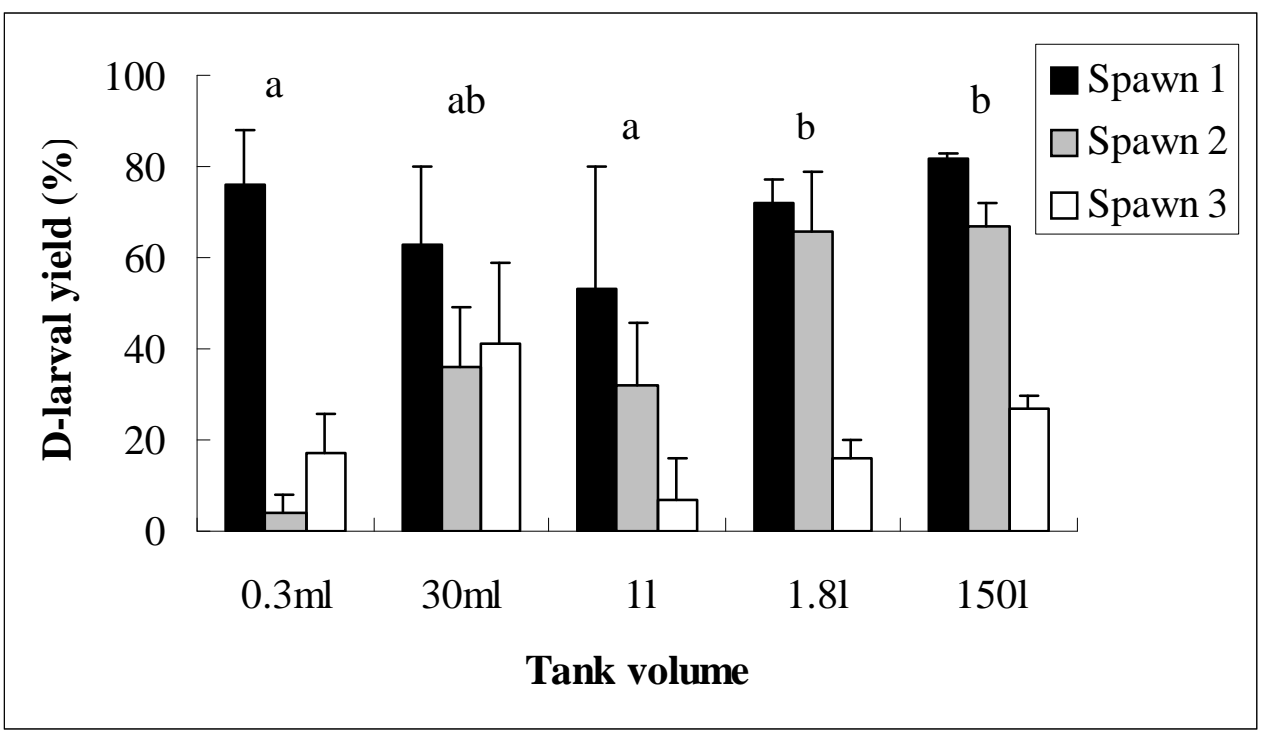

Fig.4: Effect of tank volume on D-larval yield (different letters refer to significantly different results). 


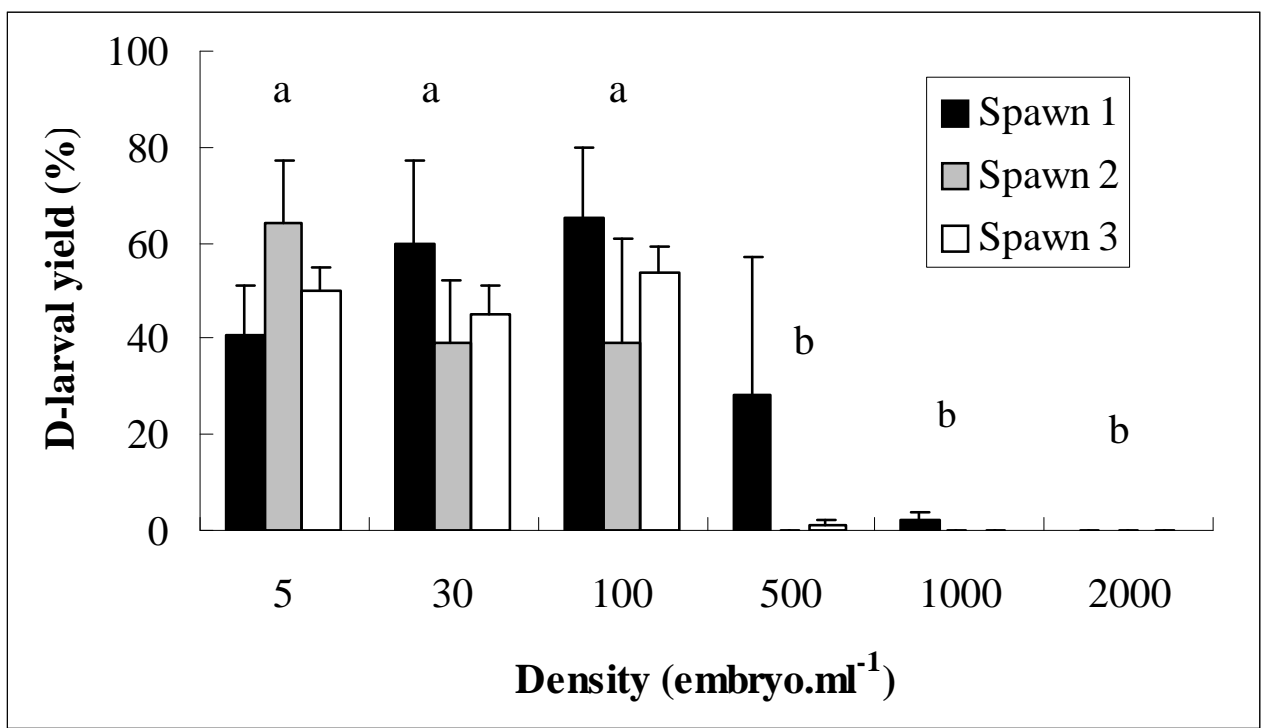

Fig.5: Effect of embryo density on D-larval yield (different letters refer to significantly different results).

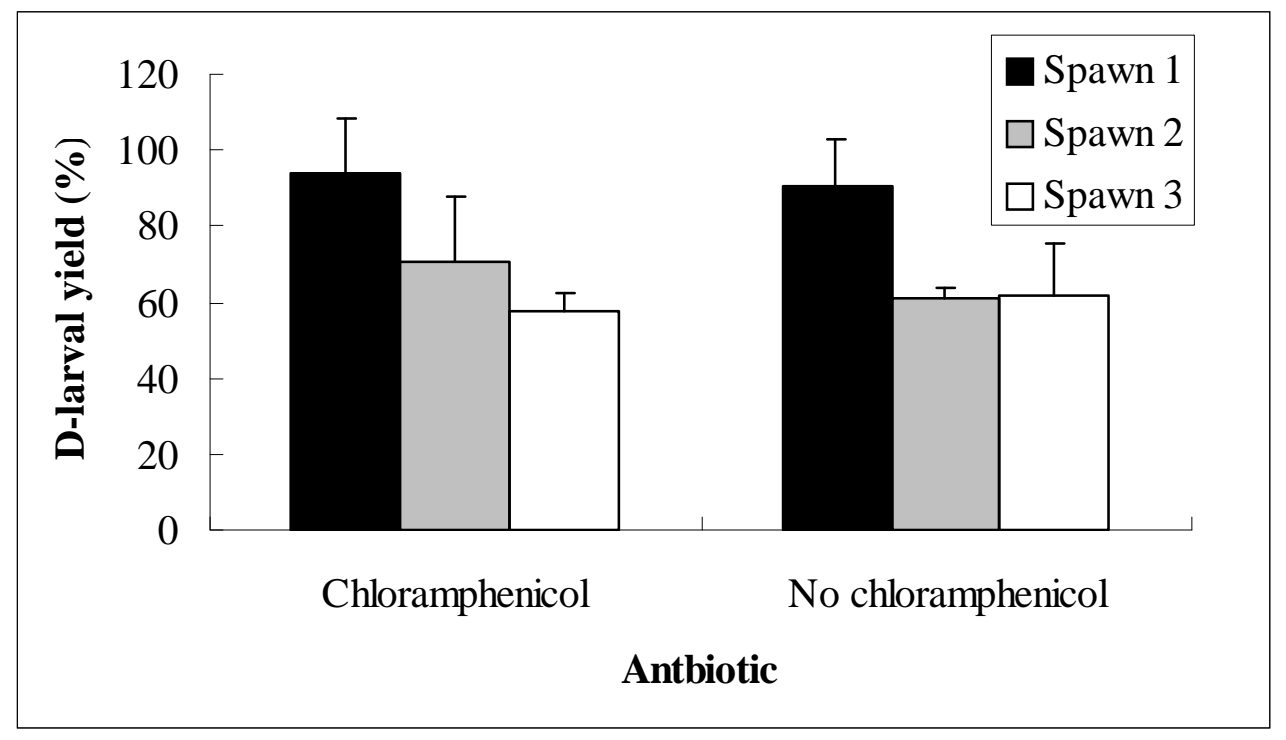

Fig.6: Effect of chloramphenicol on D-larval yield. 


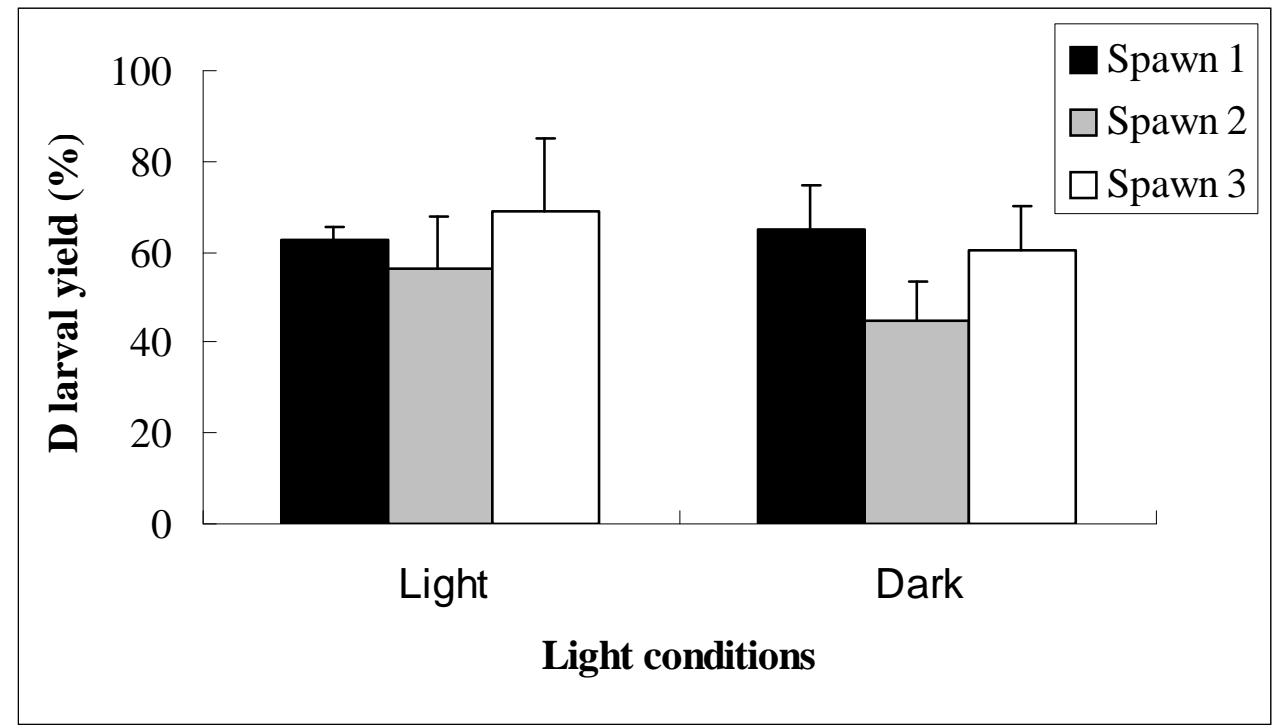

Figure captions

Fig.7: Effect of light intensity on D-larval yield.

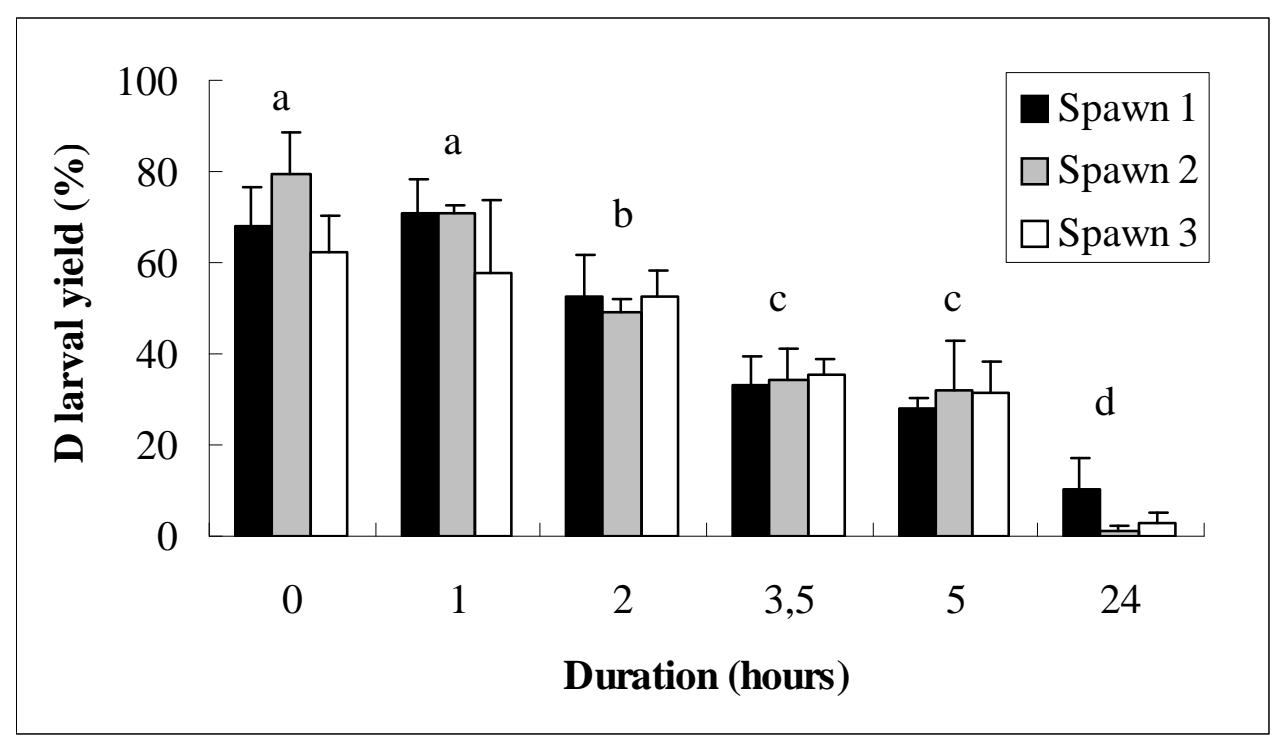

Fig.8: Changes of D-larval yield in relation with embryo maintaining period in a test tube (different letters refer to significantly different results). 


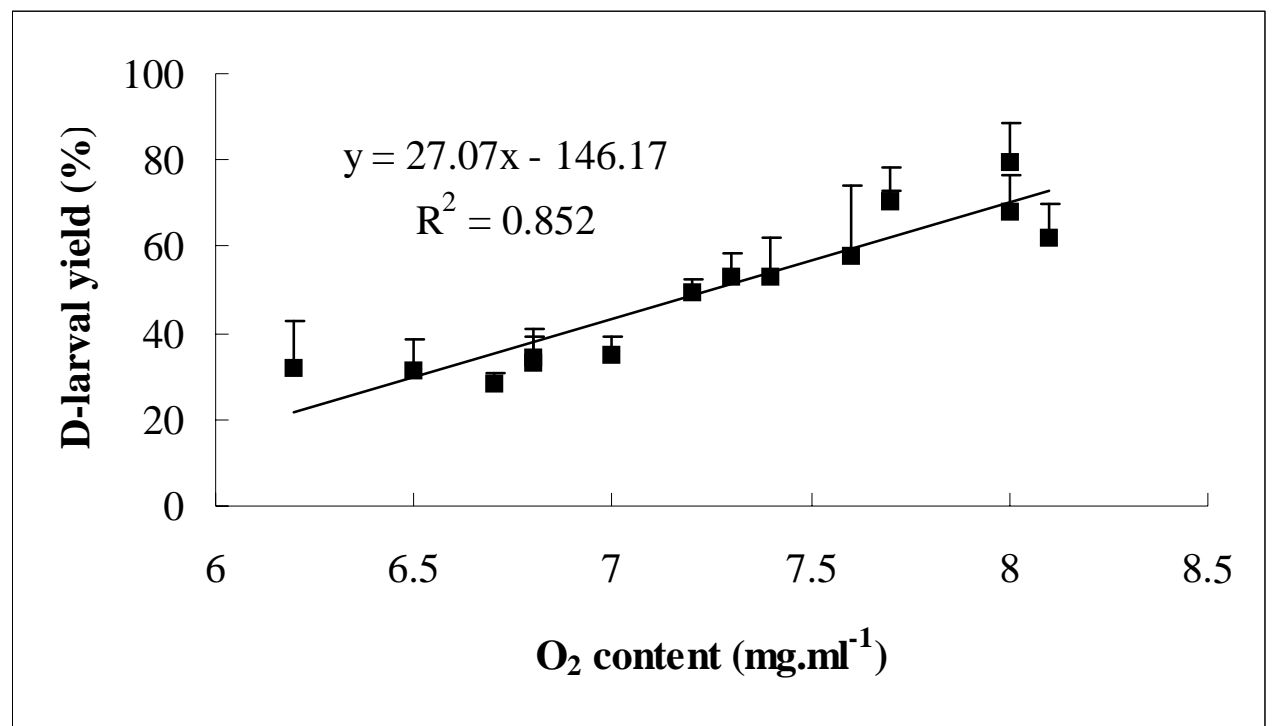

Fig.9: Correlation between oxygen content of seawater and D-larval yield.

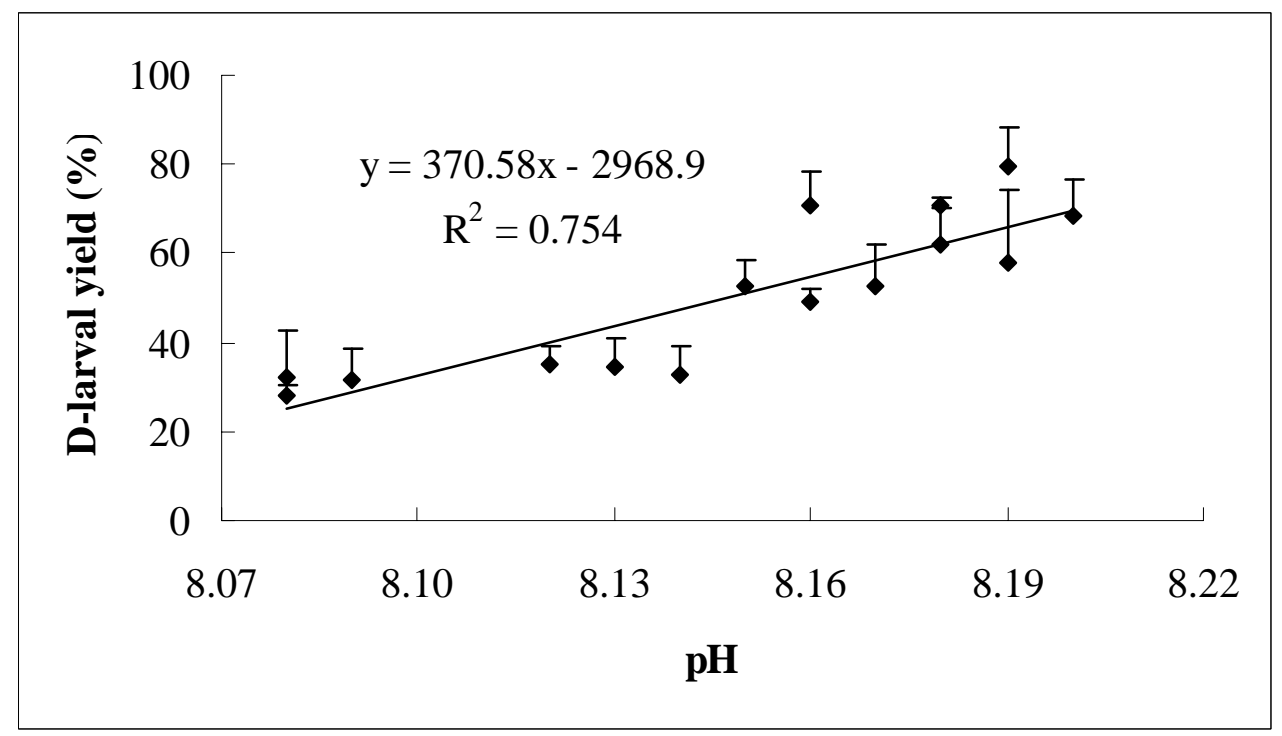

Fig.10: Correlation between $\mathrm{pH}$ of seawater and D-larval yield. 


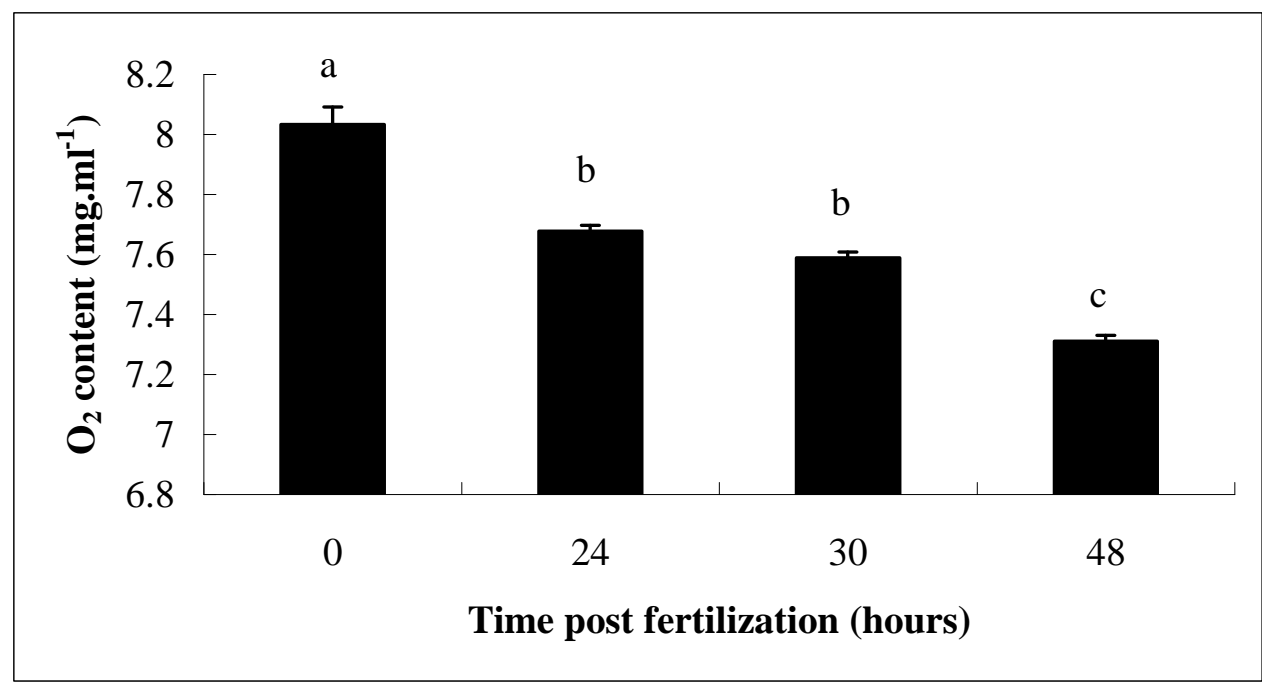

Fig.11: Changes of $\mathrm{O}_{2}$ content with time during the incubation phase (different letters refer to significantly different results).

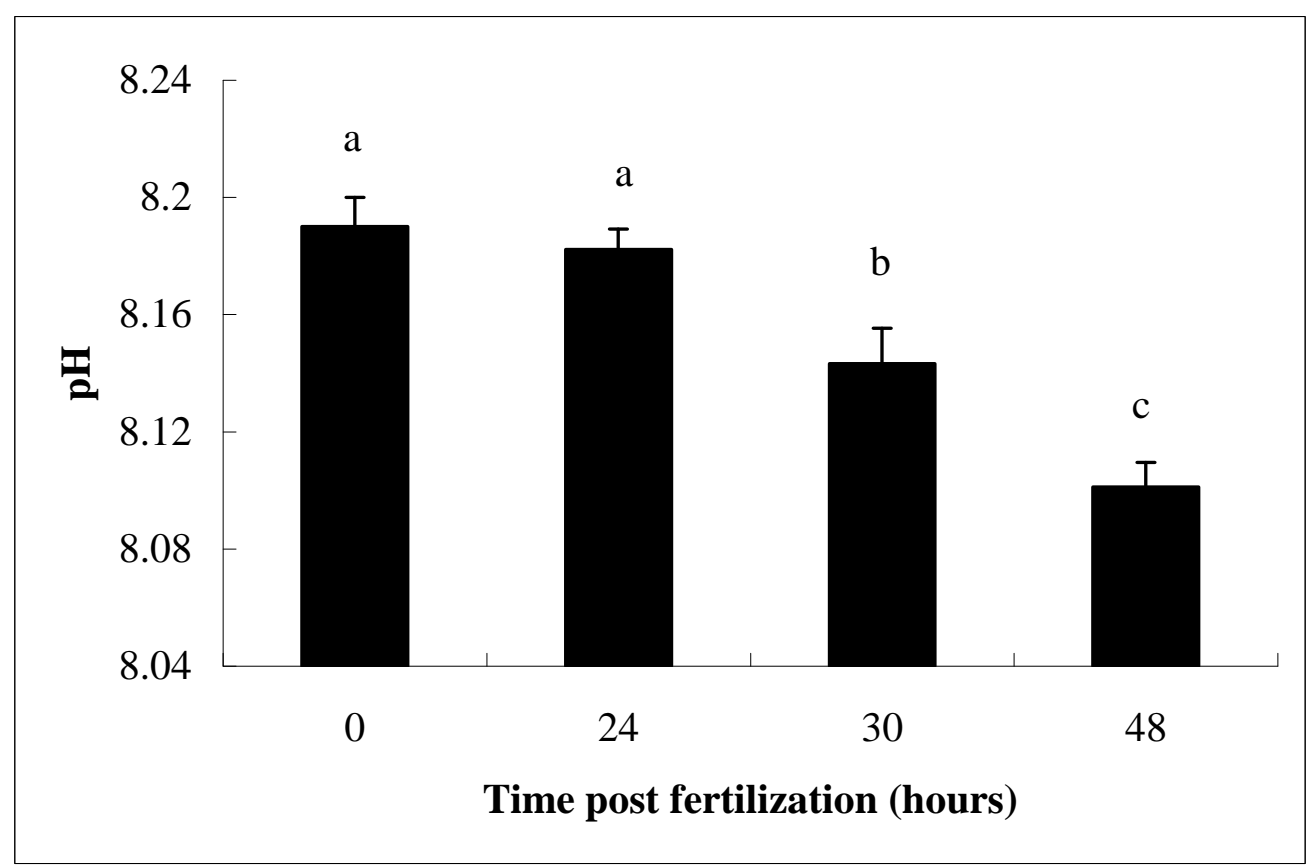

Fig.12: Changes of $\mathrm{pH}$ with time during the incubation phase (different letters refer to significantly different results). 